\title{
A Survey on Smartphone-Based Accident Reporting and Guidance Systems
}

\author{
Alexandra Fanca ${ }^{1}$, Adela Puscasiu ${ }^{2}$, Honoriu Valean $^{3}$, Silviu Folea $^{4}$ \\ Department of Automation \\ Technical University of Cluj-Napoca \\ Cluj-Napoca, Romania
}

\begin{abstract}
Every day, around the world, a large percentage of people die from road accidents and falls. One of the reasons for a person's death during accidents is the unavailability of first aid, due to the delay in informing about the accident. Thus, in the case of incidents involving vehicles or falls, response time is crucial for the timely provision of emergency medical services. An effective approach intended to reduce the number of trafficrelated deaths is: the use of a system for detecting and reporting the occurred accidents, as well as reducing the time between the occurrences of an accident and sending the first emergency respondents to the scene of the accident. This paper presents a recent study on mobile terminal solutions (smartphones) for detecting and preventing accidents (road, falls, bicycles) and systematic comparisons of existing solutions.
\end{abstract}

Keywords-Smartphone; accident; detection algorithm; reporting accident; mobile application; sensors

\section{INTRODUCTION}

The mobile phone has become part of the daily routine of the modern man, a non-detachable assistant, a gateway to news, social media, entertainment and all forms of communication. Clearly, smartphones have penetrated every aspect of our life. Smartphone is one of the most fascinating object that compared to PC or laptop is much smaller, but with a similar processing power, easy to customize and sometimes they work as an extension of the individual [1].

Introducing operating systems on smartphones has led to the emergence of so-called applications, which are installed programs such as Google Chrome, Games, and more. Thus, each individual can install the applications they need to navigate the web, edit and share documents, access e-mail, social media account, order food and drink, find information about weather, health and fitness, e-banking, or shop online, from anywhere.

Due to the competition between smartphone manufacturers, over the years, a wide range of sensors have been built to record large amounts of data, powerful computing units and powerful communication modules. Thus, the smartphone has become a mobile platform for collecting and retrieving data. Today's smartphones include: high-resolution camera, microphone, compass, accelerometer, 3-axis gyroscope, GPS receiver, as well as high-speed $\mathrm{Wi}-\mathrm{Fi}$ and $3 \mathrm{G}$ communication capabilities. The new features added to the smartphone allow application developers to determine geographic location and user moves.
Big processing power, motion detection, wireless communications, open source operating systems, popularity, relatively low cost and, in particular, the ability to obtain a rich variety of data, make smartphones a good tool for mobile applications in the medical and safety fields.

By introducing the concept of "Internet of Things" into modern electronics, embedded sensors in smartphone have been increasingly used by mobile application developers for various types of systems such as monitoring, detection, guidance and / or reporting of human behavior in various situations such as road accidents, falls, driving inadequate, etc. [2].

Due to daily use of mobile phones, this device is perfect for detecting the fall or other types of accidents with trauma and helping the injured user to receive first aid in the shortest time.

With the increase in sales of mobile devices, the smartphone application market has grown considerably. Mobile devices, especially smartphones, have been used to monitor, detect, guide and / or report accidents in many applications, both academically and commercially. The reason why smartphones are becoming more and more used in such applications is that they can track the vehicles, determine their speed and offer traffic at a lower cost compared to the traditional approach using loop detectors. In addition, smartphones are immediately available to most users, which means there is no need for additional specialized detection hardware.

Another very important aspect discussed by researchers and application developers is to minimize false positives in smartphone detection and reporting systems. Every year a large number of accidental calls are reported by emergency services, so reducing the false rate of detection and reporting of accidents is important [3].

\section{A. The Benefits of using Smartphone in Accident Detection}

In recent years, researchers have presented in various papers and articles the benefits of using smartphones in accident and fall detection and notification systems. The main benefits of smartphone are:

- They are updated more frequently in software than vehicles and their cost is much lower;

- Using integrated sensors (such as accelerometer, GPS, gyroscope, etc.) to get a rich variety of data; 
- Smartphones are always with their owners, indicating an accident, even if the vehicle they are in is not involved in an accident (witnessing an accident);

\section{B. Major Objectives of SARGS}

The most important objective of any SARGS is the automatic detection of any accidents by using sensors embedded in the smartphone. Another important objective is to report the occurrence of an accident as soon as possible by using the real-time system, the correct records, etc.

Other objectives could be to send automatically warnings in case of accident and the possibility to cancel reporting in case of false accidents.

The rest of the paper is organized as follows: Section II describes the integrated systems in vehicles, section III presents a series of smartphone based systems and the main advantages and disadvantages of the systems, and the proposed idea is presented in Section IV, and in the section $\mathrm{V}$ are presented the conclusions.

\section{ACCIDENT DETECTION INTEGRATED SYSTEMS FOR VEHICLES}

Various types of accident prevention and detection systems have been studied and implemented over the years. Thus, various integrated automatic detection and notification systems have been developed at the time of vehicle traffic accident.

One of these systems is OnStar [4] being available only to Opel or Vauxhall car owners. This system has been running since the 1990's in the United States and since 2016 it has been introduced in Europe in thirteen countries. This system offers free trial for 3 months and is available in 8 languages. The system provides assistance for all emergencies as well as other assistance (location, car data, vehicle diagnosis, etc.). A disadvantage of this system is the impossibility to cancel the call to the emergency service if the SOS button has been accidentally pressed.

Even if the integrated systems in the vehicle are working well, they are expensive and not available for monitoring older vehicles.

\section{MOBILE APPLICATIONS FOR DETECTING AND REPORTING ACCIDENTS}

In the attempt to eliminate the false positive of an accident, various methods are integrated, such as: combining the data provided by the smartphone sensors (accelerometer, microphone, GPS, gyroscope, camera, etc.) with vehicle data collection (airbags, GPS position, etc.) by wireless communication (Wi-Fi, Bluetooth, OBD-II platform, and VANET) or the additional use of a Kalman filter.

In this section, we offer some existing applications which can be used in the event of an accident (road accidents, fall, etc.).

The paper [5] describes how smartphones can automatically detect a road accident, relying on data processing capability and built-in sensors without direct interaction with vehicle sensors. For this purpose, a mobile application called WreckWatch has been proposed that uses the accelerometer and microphone for accident detection and defines a formula based on which an accident can be assumed. WreckWatch records different types of data such as: accelerometer trajectory, acceleration and acceleration forces, images, videos, acoustic data and GPS coordinates.

Chalermpol Saiprasert and Wasan Pattara-Atikom [6] are proposing a system for reporting abnormal driving using smartphone as a terminal, due to its capabilities to collect, store and send real-time data. By collecting data from the built-in GPS of the smartphone, the user can get a driving report by analyzing the vehicle's speed over a route's distance. An algorithm capable to detect speed profile anomalies has been proposed.

In the paper [7], Hamid M. Ali and Zainab S. Alwan propose a road accident detection and notification system called CADANS. The accident detection algorithm used by Hamid M. Ali et al is based on data collection continuously from various sensors integrated into the smartphone such as: accelerometer (used to record acceleration forces (force G)), the GPS receiver (used to determine the vehicle speed, speed used to increase the probability of detecting an accident based on accelerometer data), the microphone (which determines the high acoustic events such as the airbag triggering sound ) as well as the camera / video camera (used to send videos to the emergency help center for any further analysis). The notification sent to the "help center" contains, in addition to the location of the accident, other data such as vehicle speed, acceleration force $\mathrm{G}$, airbag status, and the occurrence of the accidents.

F. J. Bruwer and M.J. (Thinus) Booysen propose in the paper [8] a way to enable reckless driving detection, using sensors in current smartphones (accelerometer, gyroscope and magnetometer), relying primarily on vehicle acceleration. The main objective pursued in this paper is to eliminate the effects of the gravity vector from the acceleration measured by smartphone in a vehicle. In addition to the smartphone's builtin sensors, a Kalman filter was used to combine accelerometer, gyroscope, and magnetometer and vehicle dynamics data in a way that maximizes the probability of accurately estimating the orientation of the sensors to the Earth's axes. After estimating the gravitational acceleration, it is removed from the acceleration measured to obtain vehicle acceleration.

Bruno Fernandes et al, presents in paper [9], HDyCopilot, an Android application developed for automatically detecting road accidents with eCall and IEEE 802.11p. For the accident detection algorithm, it was chosen to combine the data collected from the vehicle (via ODB-II) with the data obtained from smartphone built-in sensors, namely accelerometer, magnetometer and gyroscope. The GSM / GPRS capabilities of the smartphone are also used to implement eCall. The proposed algorithm detects the occurrence of an accident when one of three situations occurs: triggering the airbag, overturning the vehicle or collision.

Upon detection of an accident, an alarm signal is transmitted via the IT2S platform. A road hazard warning message is automatically sent to all neighboring cars. The second alarm signal is transmitted to the EMS (Emergency 
Medical System) by making an eCall, and sending an SMS containing the minimum eCall data set.

The HDyCopilot application runs on the Android operating system, specifically chosen for allowing access to hardware components through its open source APIs.

Cano et al [10] describe an app running on smartphones with the Android operating system that connects to the car's OBD-II system to detect road accidents. The proposed solution is based on Bluetooth technology in terms of the connection between the mobile application and the OBD-II interface, eliminating the cable connection, making it robust against car accidents.

The proposed application combines vehicle data (such as the airbag condition) with those provided by the smartphone (accelerometer, GPS) to improve the effectiveness of emergency services by automatically detecting the accident.

Akshay Agrawal et al. presents in the proposed paper [11] an idea of creating a car accident detection system by implementing an adaptive algorithm. The purpose of such an application is to help save lives by alerting you to the accident. The authors proposed to use an adaptable algorithm to detect accidents in any type of machine. Being an Android application, the system will be available at a low price, also available for low-end vehicles and usable in any country due to Android Market app uploading. When an accident occurs, the proposed system will detect it, then with the front and main camera, events are taken, and an SMS will be sent to the predefined contact numbers.

In the paper [12], the authors Yue Shi et al. propose a new accident detection concept using the features of a five-phase model to change the status of the user's movement during the fall. The concept of fall detection uses acceleration data provided by smartphone sensors (such as accelerometers and gyroscopes). Apply new features derived from a five-phase model describing the multi-stage drop process. A demonstration application called uCare, running on the Android operating system, is designed and implemented with the main purpose of helping people prevent and detect the fall.

Huang, Chuen-Min et al. propose a mechanism for detecting and tracking bicycle accidents based on mobile terminals [13]. In case of an accident, the proposed system uses different smartphone sensors such as accelerometer ( $G$ sensor) for detection, GPRS, Google Map and GPS for tracking and notifying the crash. To test and validate the performance of the proposed system, various hypotheses were studied, and an implementation of an Android mobile application called GoGoBike was performed.

Dr. Apps [14] launching a free mobile application that runs on smartphones with Android operating system and is called Accident Report. This is a crash application that collects different types of data to create a complex report like a PDF file, which can be send via e-mail. Creating a report involves following steps such as: drawing of the damage to the vehicle, photographing the vehicles, obtaining the location, filling in the personal details, details of the accident and information on the witnesses involved and information of the other party involved in the accident.
Beat the Traffic [15] is another Android app, developed later for the iOS operating system, which is used to report an accident automatically using the GPS. This is available in the US and Canada, with free access to camera images. An important feature of this app is "shake to report", which allows an accident to be reported by simply shaking the smartphone. To access the full functionality of the app, the user must sign up for a free account and customize the app according to his preferences.

SOSmart is a mobile app available in Google Play and the App Store for automated car accident detection using smartphone's integrated sensors. This application can also be used manually (by pressing the panic button). According to the official site [16], the application is able to automatically detect an accident using smartphone sensors such as GPS and accelerometer and can notify predefined contacts. The application also uses an algorithm that is based on real-time data provided by the National Highway Traffic Safety Administration [17], making it possible to distinguish between a landline phones, heavy braking, or a minor accident. Other features offered by the application are historical trips, as well as viewing the nearest hospitals.

Another important aspect is the ability to configure the application, depending on the users. If we talk about users who frequently travel by car, then the application can be set to automatic mode and it will start without the user intervening, running the application in the background. For people traveling less frequently, it is recommended to use manual mode, where start of race tracking is done from the application.

INRIX Traffic [18] is another application for reporting an accident and routing automatically. The application collects data from users, which are sent through real-time notifications. Reporting an accident is done through the application (at the button's push), not automatically. This application uses automated learning technologies for vehicle driving by users and personalizes routes to avoid traffic incidents. It also recommends routes and offers automatic alerts on changing road conditions such as accidents, roadblocks, etc. This application is free and available for smartphones with Android and $\mathrm{iOS}$ operating systems.

Another similar application is the Crash Notifier developed by R Systems International Limited [19] that offers automatic detection of the accident using the accelerometer and emergency notification functions after detection. For this application, the crash detection is performed using the existing accelerometer in the smartphone that is set to the $6 \mathrm{G}$ threshold. If this threshold is reached, based on the implemented algorithm, the timer starts and after 10 seconds a notification is sent to the previously established contact persons. In the case of false alarms, this can only be canceled manually in the ten seconds. If the notification has been sent and the accident is minor, or if it is not necessary to warn the contact, you can use the False Alarm button, which sends another notification and ignore the previous message. To improve the detection algorithm, the threshold value $\mathrm{G}$ can be manually configured from the application.

AxiKit is a step-by-step accident tracking application that stores different types of data, voice recordings, mapping the 
location of the accident (date and time) automatically, capturing details with the camera, making a detailed report which can be easily transmitted by email [20]. The application also provides an emergency button for the user to call emergency services and a predefined contact person. It was originally only available for the iOS operating system, being optimized for the iPhone 5, but behind some updates, it also runs on the Android operating system.

CRADAR is a free Android application offered by ActionXL, which is used in case of an accident [21]. This application uses the phone's accelerometer to detect a fall and GPS to identify the location of the crash. The algorithm analyzes the data collected from the accelerometer and detects when the user falls. After detecting such an accident, the phone starts ringing and vibrating, and a counter will start. If the phone notices movements or the "I'm OK" button is pressed before the time expires, the alert is canceled, and the application goes back to the monitoring mode. After the default time has elapsed, a message containing accident location data (provided by the GPS) is sent to the established emergency contact.

Annex 1 lists the main advantages and disadvantages, the operating system and the sensors used for each system described above.

\section{PROPOSED IDEA AND FURTHER RESEARCH}

People's safety and health is a lasting global concern. Every day, many human lives are lost due to accidents and delays in calling for rescue services [22]. Researchers are looking for a solution to reduce the loss of these lives. This delay is caused by various reasons. The most common is the lack of proper communication to emergency services.

An effective system is proposed to automatically notify these services of the accident and to guide them on the spot. In addition to other accident report systems, the proposed system will be able to detect different types of accidents, starting from simple falls to traffic accidents with serious injuries.

As shown in this paper, the smartphones can detect the occurrence of an accident, but the main problems remain the high rate of false detection. Different from other systems, our system will learn the user's daily behavior. For this we can use different machine learning algorithms such as neural networks [23], support vector machine (SVM) or decision tree. In the beginning, the system will work in the learning phase and after that it can be used being able to minimize false detection.

Based on the research presented, it has been found that the Android operating system is open source, more permissive with the use of embedded sensors, and phones with this operating system are much cheaper than iPhone smartphones.

Therefore, Android will be used as the main platform for designing and deploying the demonstration application, for implementing services, accident detection, emergency event reporting, and testing the functionality of the proposed system.

\section{CONCLUSION}

In this paper are presented a series of systems used in case of accident based on mobile terminals such as smartphone, and the importance of their use in emergency situations. For each system it is highlighted how it works, the operating system on which applications are running, and the main advantages and disadvantages.

Chapter III present some of the existing applications for detecting an accident using smartphone built-in sensors. The user can choose the desired application, considering several features such as: the phone's operating system, the sensors used for detection and the additional features offered by each application.

\section{REFERENCES}

[1] The ecomonist (2015), Planet of the phones, Smartphone ubiquitous addictive and transformative plantet phones, Available:https://www.economist.com/news/leaders/21645180smartphone-ubiquitous-addictive-and-transformative-planet-phones.

[2] Fortino, G, Trunfio, P., "Internet of things based on smart objects: Technology, middleware and applications”, 1 January 2014, Pages 1198, ISBN: 978-331900491-4;

[3] Erwin A. Blackstone, Andrew J.Buck, Simon Hakim, "Evaluation of alternative policies to combat false emergency calls", Evaluation and Program Planning, Volume 28, Issue 2, May 2005, Pages 233-242.

[4] OnStar System, Official site Opel, Available: http://www.opel.ro/onstar/onstar.html

[5] Jules White, Chris Thompson, Hamilton Turner, Brian Dougherty, and Douglas C. Schmidt, "WreckWatch: Automatic Traffic Accident Detection and Notification with Smartphones", Mobile Networks and Applications, DOI: 10.1007/s11036-011-0304-8, June 2011.

[6] Chalermpol Saiprasert and Wasan Pattara-Atikom, "Smartphone Enabled Dangerous Driving Report System", 46th Hawaii International Conference on System Sciences, DOI: 10.1109/HICSS.2013.484, 2013.

[7] Hamid M. Ali et al, "Car accident detection and notification system using smartphone", International Journal of Computer Science and Mobile Computing, Vol.4 Issue.4, April- 2015, pg. 620-635, ISSN 2320-088X.

[8] F.J. Bruwer and M.J.(Thinus) Booysen, "Vehicle acceleration estimation using smartphone-based sensors", Conference: South African Transport Conference, At Pretoria, July 2015, DOI 10.13140/RG.2.1.3244.4640.

[9] Bruno Fernandes, Vitor Gomes, Joaquim Ferreira and Arnaldo Oliveira, "Mobile application for automatic accident detection and multimodal alert”, IEEE Vehicular Technology Conference, At Glasgow, July 2015, DOI: 10.1109/VTCSpring.2015.7145935.

[10] J. Z. C. T. C. Juan Carlos Cano, Pietro Manzoni, "Providing Accident Detection in Vehicular Networks Through OBD-II Devices and Android based Smartphones," in Proceedings of the 5th IEEE Workshop On User Mobility and Vehicular Networks, December 2011, DOI: $10.1109 / \mathrm{LCN} .2011 .6115556$.

[11] Akshay Agrawal, Anand Khinvasara, Mitali Bhokare, Sumit Kaulkar, Prof. Y. K. Sharma, "Accident detection system application", International Journal of Emerging Technologies in Computational and Applied Sciences (IJETCAS), Issue 6 Volume 5, pp. 425-428, ISSN : 2279-0055.

[12] Yue Shi, Yuanchun Shi, Xia Wang, "Fall Detection on Mobile Phones Using Features from A Five-phase Model", Ubiquitous Intelligence \& Computing and 9th International Conference on Autonomic \& Trusted Computing (UIC/ATC), October 2012 , DOI: 10.1109/UICATC.2012.100.

[13] Chuen-Min Huang, Yen Chang. "A mobile-based novice accident detection and tracking system for bicycle", Available:https://www.researchgate.net/publication/267977300_A_MO BILE-BASED_NOVICE_ACCIDENT_DETECTION_AND_TRACKI NG_SYSTEM_FOR_BICYCLE.

[14] Accident Report Application (2015), Available online: https://play.google.com/store/apps/details?id=com.rany.accidentreport.e $\mathrm{n}$, Developer of the application Drapps, Available online: http://drapps.info/. 
[15] Beat the Traffic application (2017), Available online: http://www.appsapk.com/beat-the-traffic/.

[16] SOSmart application (2017), Available online: http://www.sosmartapp.com/.

[17] National Highway Traffic Safety Administration, Available online: https://www.nhtsa.gov/.

[18] INRIX application (2016), Available online: http://inrix.com/mobileapps/.

[19] Crash Notifier (2017), Developer of the application: R Systems International Limited, Available online: http://www.rsystems.com/.
[20] AxiKit application, Available http://www.axikit.com/fleet\#AxiKit-Mobile-App.

[21] Cradar Application, http://actionxl.com/CRADAR.html.

Available online:

[22] 10 Leading Causes of Death, West 2000 - 2015, Available online: https://webappa.cdc.gov/cgi-bin/broker.exe.

[23] M. Soltane, M. Ismail, ZAA Rashis. "Artificial Neural Network Approach to PPG Signal Classification", International Journal of Computing and Information Science, Vol 2. No 1 2004, pp. 58-65.

ANNEX 1

\begin{tabular}{|c|c|c|c|c|c|}
\hline \multirow[b]{2}{*}{ No } & \multicolumn{5}{|l|}{ Solutions } \\
\hline & $\begin{array}{l}\text { Name of } \\
\text { system }\end{array}$ & $\begin{array}{l}\text { Operating } \\
\text { system }\end{array}$ & Sensors used & Advantages & Disadvantages \\
\hline 1 & WreckWatch & $\begin{array}{l}\text { It's not } \\
\text { specified }\end{array}$ & AccelerometeMicrophone GPS & $\begin{array}{l}\text { Sensor smartphones can measure forces } \\
\text { closer to those of victims; } \\
\text { Reduce the complexity of software } \\
\text { maintenance through smartphone update } \\
\text { mechanisms. }\end{array}$ & $\begin{array}{l}\text { Accident detection systems consume a } \\
\text { significant amount of battery power; } \\
\text { Low speed traffic can trigger } \\
\text { WreckWatch service deactivation. }\end{array}$ \\
\hline 2 & $\begin{array}{l}\text { Smartphone } \\
\text { Enabled } \\
\text { Dangerous } \\
\text { Driving } \\
\text { Report } \\
\text { System }\end{array}$ & $\begin{array}{l}\text { It's not } \\
\text { specified }\end{array}$ & GPS & $\begin{array}{l}\text { The values obtained by the three } \\
\text { smartphones used in the experiments are } \\
\text { the same as those provided by the vehicle's } \\
\text { speedometer, resulting in a high GPS } \\
\text { accuracy; }\end{array}$ & $\begin{array}{l}\text { The way the data is received, the } \\
\text { reception condition affects the accuracy } \\
\text { and sensitivity of the recording data; The } \\
\text { position of the smartphone in the vehicle } \\
\text { has an effect on the correctness of the } \\
\text { recorded data; }\end{array}$ \\
\hline 3 & CADANS & $\begin{array}{l}\text { It's not } \\
\text { specified }\end{array}$ & $\begin{array}{l}\text { AccelerometerGPS } \\
\text { Microphone Camera }\end{array}$ & $\begin{array}{l}\text { Combining the data provided by the sensors } \\
\text { and determining whether the occupant is } \\
\text { inside or outside the vehicle helps to } \\
\text { minimize falsities; } \\
\text { CADANS offers the possibility of } \\
\text { canceling the alarm and notifications if a } \\
\text { false accident has been detected by pressing } \\
\text { a cancel button within } 10 \text { seconds of the } \\
\text { accident detection; }\end{array}$ & $\begin{array}{l}\text { Testing the system in a real environment } \\
\text { (car crash) is not realistic and possible; } \\
\text { Microphones built into smartphones differ } \\
\text { from brand to brand, some have set a } \\
\text { maximum threshold of } 140 \mathrm{db} \text {, making it } \\
\text { hard to distinguish the sound produced by } \\
\text { the airbag and the maximum volume of } \\
\text { the radio; }\end{array}$ \\
\hline 4 & $\begin{array}{l}\text { Vehicle } \\
\text { acceleration } \\
\text { estimation } \\
\text { using } \\
\text { smartphone- } \\
\text { based } \\
\text { sensors* }\end{array}$ & $\begin{array}{l}\text { It's not } \\
\text { specified }\end{array}$ & $\begin{array}{l}\text { AccelerometerMagnetometerGyroscope } \\
\text { Kalman filter }\end{array}$ & $\begin{array}{l}\text { The proposed system is capable of } \\
\text { detecting low acceleration values, which is } \\
\text { beneficial for the development of mobile } \\
\text { applications where low-speed acceleration } \\
\text { is of interest. }\end{array}$ & $\begin{array}{l}\text { A disadvantage discovered after } \\
\text { comparing measured results with those } \\
\text { calculated theoretically show that in case } \\
\text { of an accident in which the vehicle } \\
\text { overturns, Kalman filtering operation is } \\
\text { adversely affected. }\end{array}$ \\
\hline 5 & HDyCopilot & Android & $\begin{array}{l}\text { Accelerometer Magnetometer } \\
\text { Gyroscope vehicle sensors }\end{array}$ & $\begin{array}{l}\text { To avoid reporting a fake accident, alert } \\
\text { notifications can be canceled within a } \\
\text { certain amount of time via the mobile } \\
\text { application }\end{array}$ & $\begin{array}{l}\text { The disadvantages of the system are not } \\
\text { presented in this paper. }\end{array}$ \\
\hline 6 & $\begin{array}{l}\text { Providing } \\
\text { Accident } \\
\text { Detection in } \\
\text { Vehicular } \\
\text { Networks } \\
\text { Through } \\
\text { OBD-II } \\
\text { Devices and } \\
\text { Android } \\
\text { based } \\
\text { Smartphones }\end{array}$ & $\begin{array}{l}\text { It's not } \\
\text { specified }\end{array}$ & $\begin{array}{l}\text { Accelerometer, GPS } \\
\text { vehicle sensors (airbag) }\end{array}$ & $\begin{array}{l}\text { To reduce false alerts, the user can interrupt } \\
\text { sending an accident report within a set } \\
\text { interval (one minute) via the mobile } \\
\text { application. }\end{array}$ & $\begin{array}{l}\text { Using Bluetooth mode continuously } \\
\text { affects the battery life }\end{array}$ \\
\hline 7 & $\begin{array}{l}\text { Accident } \\
\text { detection } \\
\text { system } \\
\text { application }\end{array}$ & Android & $\begin{array}{l}\text { Camera, Accelerometer } \\
\text { GPS }\end{array}$ & $\begin{array}{l}\text { The adaptive algorithm has been chosen } \\
\text { because each machine has different } \\
\text { vibration inputs, being able to set accident } \\
\text { thresholds }\end{array}$ & $\begin{array}{l}\text { For the proposed system, the smartphone } \\
\text { has to be positioned in a phone holder to } \\
\text { detect machine vibrations through the } \\
\text { built-in sensors }\end{array}$ \\
\hline 8 & uCare & Android & Accelerometer Gyroscope & $\begin{array}{l}\text { It takes into account the distinction of five } \\
\text { types of fall (falling on the hands, knees, } \\
\text { back, left and right of the body) }\end{array}$ & $\begin{array}{l}\text { The disadvantages of the system are not } \\
\text { presented in this paper. }\end{array}$ \\
\hline 9 & GoGoBike & Android & $\begin{array}{l}\text { GPS } \\
\text { Accelerometer }\end{array}$ & $\begin{array}{l}\text { The advantages of the system are not } \\
\text { presented in this paper. }\end{array}$ & $\begin{array}{l}\text { Continuous use of GPS mode affects } \\
\text { battery life; } \\
\text { Reporting of the accident occurs only in } \\
\text { the adhered group; }\end{array}$ \\
\hline
\end{tabular}

*In these papers, the proposed system does not have a predefined name. 


\begin{tabular}{|c|c|c|c|c|c|}
\hline 10 & $\begin{array}{l}\text { Accident } \\
\text { Report }\end{array}$ & Android & $\begin{array}{l}\text { GPS } \\
\text { Camera }\end{array}$ & $\begin{array}{l}\text { Free application; } \\
\text { Available for Android 3.0+; }\end{array}$ & $\begin{array}{l}\text { To complete a complex report you must } \\
\text { go through many steps, and in emergency } \\
\text { situations it is difficult to achieve; }\end{array}$ \\
\hline 11 & $\begin{array}{l}\text { Beat the } \\
\text { Traffic }\end{array}$ & $\begin{array}{l}\text { Android } \\
\text { and iOS }\end{array}$ & $\begin{array}{l}\text { GPS } \\
\text { Accelerometer }\end{array}$ & $\begin{array}{l}\text { The advantages of the system are not } \\
\text { presented in this paper. }\end{array}$ & $\begin{array}{l}\text { This app is only usable for minor } \\
\text { accidents to inform drivers involved in } \\
\text { traffic, so an accident is reported only by } \\
\text { marking it on the map; }\end{array}$ \\
\hline 12 & Sosmart & $\begin{array}{l}\text { Android } \\
\text { and iOS }\end{array}$ & GPS Accelerometer & $\begin{array}{l}\text { Automatic accident detection; } \\
\text { Quick answer in case of accident; } \\
\text { Detects the crash in the absence of the } \\
\text { signal but does not report it; }\end{array}$ & $\begin{array}{l}\text { On iOS, the application must also be } \\
\text { installed by predefined contacts to receive } \\
\text { crash notifications; } \\
\text { Does not work without GPS mode turned } \\
\text { on; } \\
\text { Uses a lot of energy (battery discharge); }\end{array}$ \\
\hline 13 & $\begin{array}{l}\text { INRIX } \\
\text { Traffic }\end{array}$ & $\begin{array}{l}\text { Android } \\
\text { and iOS }\end{array}$ & GPS & $\begin{array}{l}\text { INRIX uses a cloud platform, Autoelligent; } \\
\text { In addition to the main features, this app } \\
\text { also offers some additional features; }\end{array}$ & $\begin{array}{l}\text { A major drawback of the application is } \\
\text { the continued use of GPS in the } \\
\text { background that drastically reduces } \\
\text { battery life; }\end{array}$ \\
\hline 14 & $\begin{array}{l}\text { Crash } \\
\text { Notifier }\end{array}$ & Android & Accelerometer & $\begin{array}{l}\text { Application is free and available on Google } \\
\text { Play }\end{array}$ & $\begin{array}{l}\text { Setting the manual threshold inside the } \\
\text { application can result in false detection of } \\
\text { an accident }\end{array}$ \\
\hline 15 & AxiKit & $\begin{array}{l}\text { Android } \\
\text { and iOS }\end{array}$ & $\begin{array}{l}\text { Camera, Microphone } \\
\text { GPS }\end{array}$ & $\begin{array}{l}\text { AxiKit can be downloaded for both } \\
\text { operating systems for free; }\end{array}$ & $\begin{array}{l}\text { Is also a personalized application that } \\
\text { involves paying costs, and is generally } \\
\text { intended for large companies; }\end{array}$ \\
\hline 16 & Cradar & Android & Accelerometer GPS & $\begin{array}{l}\text { In order not to affect the life of the battery, } \\
\text { CRADAR uses the GPS only when a fall is } \\
\text { detected. }\end{array}$ & $\begin{array}{l}\text { The disadvantages of the system are not } \\
\text { presented in this paper. }\end{array}$ \\
\hline
\end{tabular}

